\section{Edycasáa

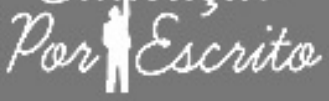

EDITORIAL

\section{Editor}

Alexandre Anselmo Guilherme PUCRS, RS, Brasil

\section{Editor Assistente}

Cibele Cheron

PUCRS, RS, Brasi

\section{Editores Associados}

Bruno Antonio Picoli

Universidade Federal da Fronteira Sul, Chapecó, SC, Brasil

Pricila Kohls dos Santos

Universidade Católica de Brasília,

Brasília, DF, Brasil

Renato de Oliveira Brito

Universidade Católica de Brasilia,

Brasilia, DF, Brasil

Elisa Ustarroz

PUCRS, Porto Alegre, RS, Brasil

\section{ISSN 2179-8435}

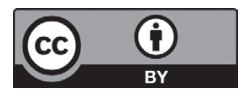

Este artigo está licenciado sob forma de uma licença Creative Commons Atribuição 4.0 Internacional, que qualquer meio, desde que a publicaçăo original seja corretamente citada. http:///creativecommons.org/licenses/by/4.0/deed.pt_BP

\title{
Complexidade como uma proposta de desafio para pensar a Educação "fora da caixa"
}

Complexity as a challenging proposal to think Education "outside the box"

\section{Alexandre Anselmo Guilherme (i) 1 Cibele Cheron (1) $^{1}$}

${ }_{1}^{1}$ Pontifícia Universidade Católica do Rio Grande do Sul (PUCRS), Porto Alegre, RS, Brasil.

\begin{abstract}
"Se a complexidade não é a chave do mundo, mas o desafio a enfrentar, por sua vez o pensamento complexo não é o que evita ou suprime o desafio, mas o que ajuda a revelá-lo, e às vezes mesmo a superá-lo."
\end{abstract}

(Edgar Morin $)^{1}$

trecho em epígrafe é a frase final do prefácio da obra "Introdução ao pensamento complexo", na qual Edgar Morin nos instiga a pensar a complexidade como proposta de desafio às nossas formas de ser, estar, conhecer e explicar o mundo. Essa proposta está no proscênio de uma perspectiva pela qual pensamos a Educação situada no mundo real, e na necessidade que as pessoas têm de, com ele, dialogar, negociar, mediar. A perspectiva da complexidade na Educação nos incita a renunciar ao pensamento simples, no qual se embasam concepções que pretendem controlar e dominar as múltiplas nuances do mundo real, disciplinando a sua miscelânea de vozes dissonantes, cores contrastantes, olhares divergentes e relações conflitivas.

O pensamento complexo não nos fornece respostas, como o próprio Morin trata de esclarecer: "[a] complexidade é uma palavra-problema e não uma palavra-solução" (MORIN, 2015, p. 6)". Então, como o pensamento complexo pode nos ajudar a buscar soluções, se a complexidade faz parte dos problemas? Marilda Aparecida Behrens (2006, p. 21) nos dá algumas pistas quando afirma que a "complexidade não é apenas um ato intelectual, mas também o desenvolvimento de

\footnotetext{
1 MORIN, 2015, p. 8.
} 
novas ações individuais e coletivas que permitam desafiar os preconceitos, que lancem novas atitudes para encarar a vida, que gerem enfrentamentos dos medos e conquistas".

Assim, um primeiro passo para pensarmos a Educação nesse "paradigma da complexidade" (MORIN, 1996), é questionarmos o paradigma conservador, newtoniano-cartesiano, ancorado na fragmentação e em visões dicotomizadas do universo, que influenciou grandemente a Educação, as práticas pedagógicas e a escola até este início de milênio. A adoção do pensamento complexo nos auxilia a compreender as mutilações e os reducionismos que as binariedades e as universalizações do paradigma anterior acarretaram não só ao exercício da docência, mas também à constituição das identidades e das interações dos sujeitos no âmbito escolar e ao conhecimento produzido e difundido nesses moldes.

Nesse sentido, o segundo volume de 2019 da revista Educação Por Escrito oferece a seus/suas leitores/as um conjunto de artigos que, direta ou indiretamente, propõem pensar a Educação para além do que nos permite a estrutura de oposição estática entre sujeito e objeto, todo e em parte, razão e emoção, docente e discente, e outros tantos pares que, por força do paradigma tradicional, concebemos rígida e irreconciliavelmente.

No primeiro artigo, "O Professor de Educação Física em Formação: o desafio teoria-prática na construção da profissionalidade", José Augusto Ayres Florentino e Lucas Souza Santos investigam a constituição do campo dos saberes do estudante, professor em formação. $\mathrm{O}$ artigo busca compreender de que forma os estudantes, professores de Educação Física em formação, estão constituindo os seus saberes, principalmente, no que diz respeito à articulação entre teoria e prática, incluindo as tensões entre o campo da formação e o campo profissional que configuram o exercício da docência na Educação Física, e de que forma esses saberes contribuem para a construção da sua profissionalidade.

Em "Instruir deleitando: reflexões acerca de abordagens do fenômeno literário em matrizes curriculares de cursos de Letras em São Paulo", segundo artigo desse volume, Fernanda Marques Granato e Rosane Oliveira Duarte Zimmer partem da abordagem da literatura nos cursos de Ensino Superior para indagar como essa leitura conceitual da literatura afeta a prática docente e a formação dos professores. A proposta do artigo é refletir acerca da formação do educador literário à luz dos conceitos e abordagens da literatura em sala de aula, cogitando que o conceito de literatura afeta não só a sua abordagem em sala, mas também a leitura realizada do fenômeno literário, transformando o objeto de estudo.

"As Tecnologias Digitais e as Relações Interpessoais no Cotidiano das Instituições Educativas" é o terceiro artigo, no qual Diana Leonhardt dos Santos e Karen Graziela Weber Machado observam a produção científica sobre o uso das tecnologias e o desenvolvimento das relações interpessoais no cotidiano das instituições educativas em pesquisas produzidas no Brasil de 2015 a 2019. As autoras sustentam que as tecnologias digitais estão presentes desde muito cedo na vida de crianças e jovens, impactando nas suas relações interpessoais e na forma 
de verem o mundo e, nesse contexto, defendem que a unidade educativa deve aproveitar as vantagens e as potencialidades das tecnologias digitais, visando favorecer o desenvolvimento de aprendizagens significativas aos estudantes.

O quarto artigo, "Tangenciamentos entre a Filosofia da Diferença e o Ensino de Matemática", assinado por José Eduardo de Oliveira Evangelista Lanuti, relata os encaminhamentos de uma pesquisa em andamento, cuja matériaprima de investigação é uma formação docente em serviço, com professores do Ensino Fundamental. Nesse contexto, é possível observar que as aproximações entre a filosofia deleuzeana e o ensino de Matemática têm provocado mudanças de concepções e de ações dos professores participantes, questionando perspectivas de categorização e de exclusão da diferença.

Lucas Rech da Silva, no quinto artigo, relata um estudo de caso realizado com duas jovens haitianas estudantes de Ensino Médio, que teve como objetivo analisar as diferentes expressões de violência dos processos migratórios e seus cotidianos no Brasil. Dentre as diferentes violências, aprofundadas nas concepções dos autores Johan Galtung e Frantz Fanon, apenas a física não está explícita nos resultados, mas até mesmo ela é problematizada. Nesse marco, "Educação e migração haitiana: um estudo de caso a partir de Galtung e Fanon" mostra que escola pode, em certos casos, agravar as violências inerentes aos processos migratórios se não as discutir e invisibilizar a existência da diversidade em seu interior.

O sexto artigo, "Alteridade, ética e diversidades de gênero na (trans)formação de operadores do direito e da cultura jurídica", traz a visão de Camila Paola Fernandes Polônia que, orientada pela Professora Cibele Cheron, debate a importância de as questões inerentes às diversidades de gênero estarem contempladas na formação dos operadores do Direito. Partindo da constatação do esgotamento da cultura jurídica centrada nos valores e nas práticas adversariais, de maximização do ganho individualista e da desumanização das relações sócio-políticas, o estudo filia-se ao entendimento de que diferentes saberes estão relacionados a diferentes costumes, condutas e práxis. Assim, transformações na matriz de conhecimentos que formam cidadãos têm potencial para produzir transformações nas relações sociais.

Rozieli Bovolini Silveira e Mariglei Severo Maraschin, em “"Queremos ser sujeitos do sistema educacional': as implicações do Trabalho Pedagógico na Permanência e Êxito de estudantes na Educação Profissional e Tecnológica”, analisa a política denominada Programa Permanência Exxito (PPE), buscando avaliar as possíveis relações entre o Trabalho Pedagógico e o sucesso ou fracasso escolar. Assim, o sétimo artigo dessa edição parte de uma concepção crítica da Educação para compreender as duas formas identificadas de trabalho pedagógico: a) quando o estudante se sente acolhido pela instituição; ou b) quando as relações reafirmam a exclusão, pretensamente selecionando os mais "aptos". 
O oitavo artigo, "Os sentidos do ensino de Filosofia no ensino médio: uma abordagem fenomenológica", de Williams Nunes da Cunha Junior, busca compreender os sentidos que professores e alunos detêm sobre a prática do ensino de Filosofia na qual esses sujeitos estão inseridos. A Filosofia é concebida como processo de criação constante que contribui para o ato de pensar. O autor convida a refletir sobre as possibilidades que o ensino de Filosofia representa, destacando a sua responsabilidade para auxiliar os estudantes a questionarem criticamente o mundo.

Em "O impacto da participação dos pais e encarregados de educação na gestão escolar: um estudo realizado na escola do I Ciclo Elimabe I em Malanje”, nono artigo, João Isarael Cabamba destaca a essencialidade do engajamento das famílias nos processos de ensino e de aprendizagem em Angola, concebendo o educando como aquele que terá a missão fundamental de assumir diferentes papeis para o desenvolvimento sustentável e integral da sociedade, por todas as suas vertentes. Defende, desse prisma, que a escola promova uma gestão participativa, fazendo com que todos os agentes educativos cooperem, compartilhando a responsabilidade pela qualidade na Educação.

No $10^{\circ}$ artigo, "Dificuldades de comunicação em um curso de licenciatura para os anos iniciais na modalidade de Ensino a Distância", Alberto Luiz Pereira da Costa emprega a Análise do Discurso para observar as interações entre os docentes e os tutores de um Curso oferecido por uma Universidade Pública do Paraná na modalidade Ensino a Distância (EAD). Os problemas percebidos pelo autor conduzem a um diálogo mais amplo, acerca das dificuldades de comunicação nos processos de ensino e aprendizagem que se estabelecem na plataforma EAD.

Juliana Thomas, autora do $11^{\circ}$ artigo, "Ensino além da visão: ferramentas e estratégias que auxiliam a inclusão do deficiente visual em sala de aula", também analisa dificuldades enfrentadas na prática docente. A autora propõe uma discussão sobre os recursos educativos voltados para discentes com deficiência visual disponibilizados pela Universidade do Vale do Taquari (Univates), bem como as inseguranças, enfrentamentos e algumas dúvidas dos professores em relação ao processo inclusivo, o qual, apesar de instrumentalizado por recursos e ferramentas fornecidos pela instituição de ensino, ainda conta com baixa adesão de discentes deficientes visuais.

A perspectiva estudantil é contemplada no $12^{\circ}$ artigo, "Uma breve síntese do perfil de alunos bolsistas em uma Universidade comunitária do RS: contribuições para a trajetória acadêmica na graduação". Nele, Malu Santarem Schuh, Maria Elisabete Machado e Alam de Oliveira Casartelli traçam uma síntese do perfil de alunos bolsistas matriculados nos cursos de graduação de uma universidade comunitária gaúcha, partindo do pressuposto que conhecer a realidade experimentada por esses sujeitos favorece possíveis contribuições para com as suas trajetórias de formação.

Enfocando a formação de professores, o $13^{\circ}$ artigo, assinado por Adriana Claudia Martins e Eliane Aparecida Galvão dos Santos, apresenta as experiências vivenciadas com a formação inicial de professores, tendo como objetivo discutir sobre o papel do diário de aprendizagem como um instrumento de interlocução na sala de aula 
universitária, entre professor formador e os acadêmicos. Nesse prisma, "A escrita acadêmica na formação inicial de professores: diários de aprendizagem na constituição de si" propõe a escrita de si como possibilidade de reflexão durante o processo formativo, considerando os movimentos de autorregulação de ser professor em formação a partir dos desafios desse processo.

O 14ㅇaㅁigo, "Múltiplos olhares de estudantes de um curso de licenciatura sobre a docência orientada: reflexões necessárias" traz as considerações de Mariane Carloto da Silva, Sandra Regina Costa Pereira e Silvia Maria de Oliveira Pavão sobre os resultados de uma pesquisa desenvolvida em uma Universidade Federal, localizada no estado do Rio Grande do Sul. A investigação aborda as percepções dos estudantes de um curso de licenciatura em relação à Docência Orientada, e aponta contribuições para a apropriação dos conhecimentos ensinados durante a disciplina, destacando a importância da atuação dos professores em sala de aula. O artigo aponta, ainda, a necessidade de alguns ajustes em relação à forma de apresentação da Docência Orientada proposta aos estudantes de graduação, sendo importante a ampliação do exercício dessa diante do potencial formativo para todos os envolvidos.

O último artigo, "A formação de gestores escolares: a dimensão ética em questão", de Marli Dias Ribeiro, Luiz Siveres e Renato de Oliveira Brito, nos apresenta um estudo em duas escolas de Educação Básica do Distrito Federal (DF), investigando a relevância da formação continuada oferecida aos gestores escolares e a efetividade dessas formações. Essa contribuição conclui que novas abordagens aprofundando as dimensões pedagógicas e administrativas devem ser oferecidas, ainda atentando para um fortalecimento da dimensão ética da formação.

Desejamos que as importantes reflexões trazidas pelas autoras e pelos autores da presente edição sejam de grande valia para auxiliar a todas e todos delinearem as possibilidades de uma Educação pensada "fora da caixa". Boas leituras!

\section{Referências}

BEHRENS, Marilda Aparecida. F. Paradigma da complexidade: metodologia de projetos, contratos didáticos e portfólios. Petrópolis: Vozes, 2006.

MORIN, Edgar. Ciência com consciência. Ed. revista e modificada pelo autor. Rio de Janeiro: Bertrand Brasil, 1996.

MORIN, Edgar. Introdução ao pensamento complexo. Tradução de Eliane Lisboa. 5. ed. Porto Alegre: Sulina, 2015.

Enviado em: 17/12/2019.

Aprovado em: 20/12/2019.

Publicado em: 17/4/2020.

Educação Por Escrito, Porto Alegre, v. 10, n. 2, jul.-dez. 2019: e36688 


\section{Endereço para correspondência:}

Alexandre Anselmo Guilherme

Pontifícia Universidade Católica do Rio Grande do Sul (PUCRS)

Av. Ipiranga, 6681, Prédio 8, sala 304.13 - Partenon

97010-082, Porto Alegre, RS, Brasil

\section{Autores:}

Alexandre Anselmo Guilherme

Doutor em Educação. Professor Pesquisador PPGEdu/PPGP (PUCRS). Coordenador do Grupo de Pesquisas em Educação e Violência (GruPEV).

Reader da Catedra UNESCO de Juventude, Educacao e Sociedade (UCB - Brasília). Editor da revista Educação Por Escrito do PPGEDU/PUCRS.

Orcid: https://orcid.org/0000-0003-4578-1894

E-mail: alexandre.guilherme@pucrs.br

\section{Cibele Cheron}

Pós-doutorado em Educação (PUCRS). Doutora em Ciência Política (UFRGS). Mestre em Ciências Sociais (PUCRS). Bacharel em Ciências Jurídicas e Sociais (UFRGS). Professora Universitária da PUCRS. Pesquisadora associada ao Grupo de Estudos do Sul Global (UFABC) e ao Núcleo Interdisciplinar de Estudos sobre Mulher e Gênero (UFRGS). Mediadora judicial certificada (TJRS). Editora Assistente da revista Educação Por Escrito do PPGEDU/PUCRS

Orcid: https://orcid.org/0000-0003-3501-5248

E-mail: iccibele@gmail.com 